\title{
Sucrose-free milk chocolate manufacture using bulking agents and a non-caloric sweetener
}

\author{
Carolina AGUILAR-VILLA ${ }^{1}$, Elly Vannesa ACOSTA-OTÁLVARO ${ }^{1}$, Eduardo RODRÍGUEZ-SANDOVAL ${ }^{2 *}$ (D), \\ Juan Camilo MAZO-RIVAS ${ }^{1}$
}

\begin{abstract}
Sucrose is important in the production of chocolates because it contributes to its texture and sensory acceptance. The aim was to evaluate the effect of adding bulking agents and a non-caloric sweetener in the preparation of a sucrose-free milk chocolate. One control sample (with sucrose) and 11 treatments were taken varying the ratio between bulking agents (maltitol, polydextrose, inulin) and non-caloric sweetener (stevia), preserving the sweetness of control. Sensory acceptance of each treatment was evaluated by preference tests and taste profile. Principal component analysis (PCA) showed that formulations with maltitol and stevia (F7); and maltitol, polydextrose, inulin and stevia (F10) were the most similar to control in their sensory and quality properties. Polydextrose concentration at levels higher than $25 \%$ negatively affected the product texture. F10 showed higher fiber contribution due to the presence of inulin.
\end{abstract}

Keywords: chocolate; sucrose substitution; inulin; polydextrose; maltitol; stevia.

Practical Application: Use of bulking agents and a non-caloric sweetener to replace sucrose in milk chocolate.

\section{Introduction}

In chocolate, sugars fulfill important functions that go beyond sweetening, as a bulking agent, texture modifier, flavor enhancer, and preservative. Its preference in many foods, is due to its clean sweet taste, with a rapid onset and minimum persistence, unlike other sweeteners (Aidoo et al., 2013; Tavares et al., 2014). In the substitution of sucrose in chocolate, polydextrose, inulin and maltodextrin have been used as bulking agents, showing favorable results from sensory acceptability in formulations with inulin and polydextrose combination (75:25) and (50:50), respectively (Gomes et al., 2007). Samples with maltodextrin did not show good acceptability of the product compared to control formulation (Farzanmehr \& Abbasi, 2009). Aidoo et al. (2014) mention that inulin must be combined with other bulking agent, since it increases chocolate viscosity by itself, which can impede its proper handling in the process. Shah et al. (2010) found that formulations of chocolates with inulin of high degree of polymerization, stevia, and polydextrose give rise to products with sensory and physicochemical characteristics very similar to milk chocolates sweetened with sucrose. Also, Son et al. (2018) reported that maltitol is an excellent substitution alternative, since it is not carcinogenic and has a relative sweetness very close to sucrose. The maltitol also generates properties of resistance to bloom in the final product, which could have a higher storage stability compared to chocolates containing sucrose. However, it is important to consider the challenge of achieving suitable synergy among the aforementioned ingredients, in order to guarantee the desired sensory, texture, and functional properties or similar to a sample sweetened with sucrose.

Despite the research presented, no sucrose-free milk chocolate has been made with the formulation of this study. Therefore, the aim was to evaluate the effect of adding bulking agents and a non-caloric sweetener in the manufacture of a sucrose-free milk chocolate, preserving its sensory and quality properties, since this is a decisive aspect for the acceptance and commercialization of the product (Oliveira et al., 2015; Markey et al., 2015).

\section{Materials and methods}

\subsection{Materials}

A control formulation was defined for the preparation of milk chocolate using cocoa, cocoa butter, soy lecithin CAS 8002-43-5, sucrose CAS 57-50-1, and essences. Likewise, for formulations of treatments without sucrose, same raw materials were used in the same proportions, and maltitol CAS 585-88-6, polydextrose CAS 68424-04-4, inulin CAS 9005-80-5, and stevia CAS 57817-89-7 as substitutes for sucrose. Inulin and polydextrose are considered bulking agents. Stevia is a natural sweetener and maltitol has functions of both bulking agent and sweetener. The sweetness power of sucrose in the product corresponds to $44 \%$. This value was calculated based on ingredients that contribute sweetness to milk chocolate such as sucrose, whole milk powder, and whey powder (Equation 1). Table 1 shows different combinations of sucrose substitute ingredients in each treatment. Percentages of 
Table 1. Variation of ingredients for each formulation regarding the replacement of sucrose with a sweetness power of $44 \%$ in the product.

\begin{tabular}{|c|c|c|c|c|c|c|c|c|c|c|c|}
\hline \multirow{2}{*}{ Ingredients } & \multicolumn{11}{|c|}{ Treatments } \\
\hline & F1 & $\mathrm{F} 2$ & F3 & $\mathrm{F} 4$ & F5 & F6 & F7 & F8 & F9 & F10 & F11 \\
\hline Inulin & 32.8 & 49.7 & 25 & 25 & 68 & 31.6 & 0 & 0 & 27 & 39 & 9.8 \\
\hline Polydextrose & 33 & 25 & 49.7 & 25 & 31.6 & 68 & 0 & 27 & 0 & 9.8 & 39 \\
\hline Maltitol & 34 & 25 & 25 & 49.8 & 0 & 0 & 99.9 & 72.8 & 72.8 & 51 & 51 \\
\hline Stevia & 0.2 & 0.3 & 0.3 & 0.2 & 0.4 & 0.4 & 0.1 & 0.2 & 0.2 & 0,2 & 0,2 \\
\hline Sweetness \% & 43.47 & 43.65 & 43.65 & 44.02 & 44.19 & 44.19 & 43.81 & 43.93 & 43.93 & 44.03 & 44.03 \\
\hline
\end{tabular}

substitutes correspond to the replacement of sucrose in control formulation taking into account its theoretical contribution of sweetness to the product. The sweetness of ingredients is expressed in relation to sucrose, which has a sweetness power of 100 (Edwards et al., 2016).

Sweetness $\%=\sum_{1}^{n} \% I D * G D$

Where $\mathrm{n}$ is the number of ingredients contributing to sweetness, $\% \mathrm{ID}$ is the participation percentage in the formulation of ingredients contributing to sweetness and GD is the sweetness degree of the ingredient.

\subsection{Sample preparation}

Both control formulation and treatments were prepared in the pilot plant of Research, Development and Quality Center-CIDCA of Compañía Nacional de Chocolates (CNC). Cocoa butter and cocoa liquor were obtained by roasting, grinding, and pressing processes carried out in the CNC's production plant. Dried raw materials were undergone to a reduction in their particle size in a refiner (Bühler, Bühler, SDY-300, Uzwil, Switzerland), to achieve a particle size close to 18 to $22 \mu \mathrm{m}$. The mixture of dry ingredients, cocoa butter, and cocoa liquor was made in a mixer (Hobart, Hobart Corporation, SE 500 Hobart, England) for $15 \mathrm{~min}$. Conching process was carried out in an equipment (Zum Wald, Maschinen- \& Apparatebau, 030321, Switzerland) with a capacity of $8 \mathrm{~kg}$ for $24 \mathrm{~h}$ at $50^{\circ} \mathrm{C}$ until obtaining a chocolate coating suitable for molding. The addition order of ingredients and additives was made according to production protocols. Then, the sample was tempered in marble slab. The tempering process began with the total melting of the chocolate fat content at $45^{\circ} \mathrm{C}$. Then, cooling with high friction was performed until the sample reached $27^{\circ} \mathrm{C}$. The chocolate sample was heated to $30^{\circ} \mathrm{C}$, molded in plastic trays and cooled down to $10-13^{\circ} \mathrm{C}$. Then, the product was subjected to cooling conditions in a refrigerator (Thermo Scientific, Thermo Fisher Scientific, Fridge Elextrolux, Waltham, MA) at $4-6^{\circ} \mathrm{C}$ and finally it was packed manually.

\subsection{Sensory analysis}

Sensory acceptance of each formulation was evaluated with a group of 6 habitual consumers of control milk chocolate. It was requested to make a qualification to the similarity of different formulations with respect to control, on a scale of 1 to 5, with their respective comments. The five highest-rated formulations in sensory acceptance analysis were subjected to a descriptive test, specifically taste profile, according to NTC 3929 of Instituto
Colombiano de Normas Técnicas y Certificación (1996), where 6 flavor attributes were compared with respect to control sample. The evaluated attributes were: sweet, dairy, chocolate, caramel, bitter, and essence. Additionally, an attribute of texture was evaluated, which was melting rate defined as the time required to melt half of the chocolate square when chewed in the mouth. The test for this last attribute was performed under NTC 4489 of Instituto Colombiano de Normas Técnicas y Certificación (1998) (texture profile methods). Tests were carried out in the sensory panel of the Center for Research, Development and Quality-CIDCA of CNC in Rionegro, Colombia, in tasting booths, using FIZZ Acquisition V 2.47 software specialized in sensory analysis (FIZZ Acquisition, Biosystemes, V 2.47, France). The panel consisted of 7 panelists previously trained under GTC 245-246 standards of Instituto Colombiano de Normas Técnicas y Certificación (2014).

In addition, a preference/similarity test was carried out between control and samples with the lowest overall distance in order to identify the most similar formulation in sensory attributes to the control sample. Test was conducted through Fizz Acquisition Software 2.51., with 21 trained and untrained panelists, using the methodology described in NTC 3939 of 2015 (ordering according to a specific criterion). Tests for flavor attributes were conducted based on the NTC 3929 of 1996 (flavor profile methods). Likewise, NTC 4489 of 1998 (texture profile methods) was used for texture attributes. During sensory tests, every judge evaluated each formula in triplicate.

\subsection{Textural and rheological measurements of the selected samples}

After performing sensory tests, two formulations were chosen and compared to control sample in their rheological and textural properties. Hardness of chocolate bars $(80 \times 14 \times 6.8 \mathrm{~mm})$ was determined using a TA XT-Plus texturometer, (TA XT-Plus, Stable Micro System, London, UK) with a probe (A/3PB, three point bend rig) and a load cell of $30 \mathrm{kgf}$. Sample was placed on two parallel supports separated at a known distance $(6 \mathrm{~mm})$ and hardness was reported as the maximum force $(\mathrm{N})$ to fracture the sample. Measurement parameters were: $1 \mathrm{~mm} / \mathrm{s}$ of pre-test speed, $2 \mathrm{~mm} / \mathrm{s}$ of test speed, and $10 \mathrm{~mm}$ of distance. Three production batchs were prepared per formulation and 7 fractures were made for each batch

For rheological tests, three production batches were prepared per formulation after conching process. Measurements were made in triplicate. The liquid samples were measured at 40 ${ }^{\circ} \mathrm{C}$ using a Physica MCR 101 rheometer (Anton Paar, Graz, Austria) equipped with a concentric cylinder geometry (inner 
diameter $26.6 \mathrm{~mm}$, outer diameter $28.7 \mathrm{~mm}$, length $40 \mathrm{~mm}$ ). Samples were melted in order to avoid formation of crystals. The flow curves were measured as function of increasing shear rate from $0.1 \mathrm{~s}^{-1}$ to $50 \mathrm{~s}^{-1}$. Data were collected using RHEOPLUS/32 software version 2.66. Chocolate rheological flow curve was fitted by using the Casson model. Casson yield stress $(\mathrm{Pa})$ and Casson viscosity (Pa.s) were determined (Glicerina et al., 2016; Aidoo et al., 2014; Beckett, 2009).

\subsection{Nutritional information}

Calculations of nutritional values of control and the sucrose-free samples, which exhibited the most similar quality and sensory attributes with respect to control, were performed using a Genesis R \& D software 11.3.289 (Genesis R \& D, Esha Products, 11.3.289, Oak Brook, USA). The amounts (g) of each ingredient must be entered into the software, which has the nutritional information of each one. Then, the software calculates the nutritional table based on the portion of the product, which in this case was $20 \mathrm{~g}$. This analysis took into account the legal requirements set forth in Resolution 333 of 2011, which establishes the requirements for labeling or nutrition labeling that food packaged for human consumption must comply with.

\subsection{Statistical analysis}

In preference tests, the global distance of sensory attributes with respect to control sample characteristics was verified in each formulation. Analysis of this data was done using Stargraphics version 5.0. (Statgraphics Technologies, Inc, version 5.0., Virginia). Results of all sensory measurement, average values and standard deviation were calculated. An analysis of variance (ANOVA) was performed. A p-value $<0.05$ was considered significant. In addition, principal component analyzes (PCA) were performed using PanelCheck 1.4.2 (PanelCheck, PanelCheck, 1.4.2, Nofima AS, Norway)

\section{Results and discussion}

\subsection{Sensory tests}

The five best formulations were obtained in results of sensory acceptance test based on their similarity to control sample, which were: F4, F7, F8, F9, F10, with the following average ratings 4.46, 4.16, 4.7, 4.08, 4.04, respectively (results not shown). These data were given by six usual consumers. The results obtained from the calculation of global distance between control and F4, F7, F8, F9 and F10 formulations through preference/similarity test are shown in Table 2. The formulations with minor distances were F7 and F10, with values of 1 and 0.87 , respectively. Results with lower distance showed that it is not possible to define which out of the two formulations (F7 and F10) had higher similarity with control sample; 10 out of 21 trained and untrained panelists mentioned that F7 formulation was the closest to control and the remaining 11 felt that F10 formulation was the most similar to control. Additionally, panelists declared that differences in texture were identified in F7 and F10 formulations. This may be due to the fact that these treatments without sucrose had high granulometry or grittiness due to the added bulking agents.

From results obtained in taste profiles of control and treatments, mean values for different attributes were taken and normalized on judges and individual repetitions (Figure 1); 75.5\% of sensory variations can be described by the first and second main components. Bidiagram provides a good description of similarities and differences of evaluated formulations. It can be seen that control sample is defined by sweet and dairy attributes. Treatments closest to control in attributes of overall liking, melting rate, and dairy flavor were F7 and F10. This was in agreement with the results obtained by calculation of distance in the previous test. Furthermore, these same samples had better overall liking, melting rate, chocolate, and dairy flavor than control formulation, being then an indication of the sensorial acceptance consumers could have about them. As seen in Figure 1, it is possible to show

Table 2. Global distance of sensory attributes with respect to control sample characteristics in preference tests.

\begin{tabular}{cccccc}
\hline & Control & F4 & F7 & F8 & F9 \\
\hline F4 & 1.50 & & & & \\
F7 & $\star 1.00$ & 1.12 & & & \\
F8 & 1.12 & 1.22 & 0.50 & & \\
F9 & 1.32 & 0.71 & 0.87 & 1.00 & \\
F10 & ${ }^{*} 0.87$ & 1.22 & 1.32 & 1.41 & 1.22 \\
\hline
\end{tabular}

${ }^{*}$ Formulations with less distance compared to control.

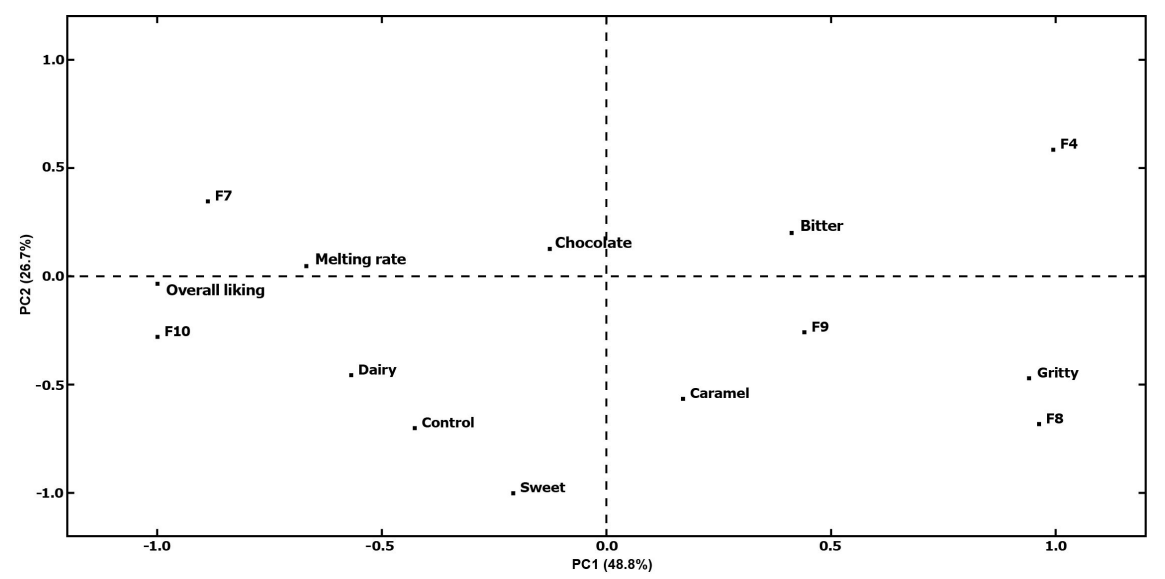

Figure 1. Principal components analysis (PCA) of sensory attributes for the formulations evaluated in preference tests. 
differences in the sweet attribute for F7 and F10 treatments, despite having made a calculation in which the sweetness level of each formulation was compared to control. However, Beckett (2009) mentioned that theoretical calculations are unable to predict the sweetness of cocoa products or other products in which part or all of sucrose is substituted by another type of sugar or another substitute of sucrose. These can only provide guidelines, however, it is always necessary to carry out sensory evaluations of sugar-free samples.

F8 formulation contained polydextrose and maltitol as bulking agents and stevia as sweetener. This treatment presented a negative sensory characteristic, which is gritty. Considering that this sample had the highest presence of polydextrose and all formulations had maltitol and stevia, even in higher amounts, it can be said polydextrose significantly affects gritty attribute of the sugar-free samples. It is important to consider a moderate presence of this ingredient, since products in which it is incorporated may be susceptible to the perception of granules. Aidoo et al. (2014) performed a microscopy analysis of different formulations containing inulin and/or polydextrose, finding variations in the microstructure of chocolate samples containing these bulking agents due to the presence of larger crystals, which increased the viscosity and possibly the granulometry. However, the calculated distance between F7 (maltitol and stevia) and F8 (maltitol, polydextrose and stevia) had the lowest value between formulations. Therefore, it is possible to conclude that polydextrose in certain proportions ( $27 \%$ substitution of sucrose for F8), may not interfere in taste but it may affect texture attributes and overall liking of sample.

On the other hand, F4 formulation is the furthest away in attributes that denote positive characteristics in products, and specifically in the most important attributes of control, such as sweet, dairy, chocolate, melting rate and overall liking (Figure 1). This result was the same obtained in distance calculation, where F4 was the furthest formulation from control sample. Replacement of sucrose in this formulation has a high presence of polydextrose (25\%), a value similar to that reported previously for F8, where it could be mentioned that the presence of granules affects texture (melting rate) and overall liking about the product.

Folkenberg et al. (1999) reported that chocolate and bitter characteristics are inversed to dairy flavor in the bidiagram interpretation. This is a theory for chocolates in general: drinks and bars. However, the substitution of sucrose, which is one of the main components of milk chocolate, by bulking agents and sweeteners, can alter the perception of chocolate and bitter taste by the judges. The bitter attribute, related to chocolate flavor, can be affected, since in many occasions sweeteners such as stevia, have associations of bitter residual taste in the mouth, produced by the presence of stevioside, and therefore this attribute is not necessarily related to the presence of cocoa, cocoa liquor, or cocoa mass (Khattab et al., 2015).

Overall liking and melting rate are inverse to gritty attribute. It is inferred that a sugar-free milk chocolate must keep the characteristics of suitable melting and particle size to achieve sensory acceptance in the consumer. This largely explains the low acceptance that consumers have for sugar-free chocolates, as they sacrifice not only flavor but also texture compared to usual chocolates. This is due to the great technological difficulty of replacing sucrose with mixtures of ingredients, which naturally modify final product texture, since they easily generate lumps in the process, are difficult to refine, have positive or negative heats of solution that give as a result different sensations in the mouth and also change the sensory experience when consuming them compared to products made with sucrose (Farzanmehr \& Abbasi, 2009; Aidoo et al., 2014; Shah et al., 2010; Beckett, 2009).

Profile analysis results showed significant differences for 4 of the evaluated attributes $(\mathrm{p} \leq 0.05)$. It is interpreted that there are differences between each treatment for sweet and melting attributes. Likewise, it occurs for gritty and overall liking attributes ( $p<0.01$ ) with 99\% confidence. Variations that occurred in each substitution imply changes in sweetness and texture attributes. Sucrose not only fulfills sweetener functions within a formulation, but also imparts suitable texture characteristics to samples, and therefore its total replacement by other ingredients, such as those used in this study, involves significant changes in the body, mouthfeel, gritty, sensation of cold or heat, among other sensorial experiences for the consumer (Afoakwa et al., 2007; Aidoo et al., 2013; Rocha et al., 2017).

\subsection{Rheological and textural properties of selected formulations}

Hardness in chocolate is directly related to the sensory perception that a consumer may have at the moment he/she tastes the product. High values of fracture resistance in chocolates are desirable, as they indicate good brightness, resistance to damage due to changes in temperature, physical changes, suitable mouthfeel, and melting rate behavior (Rezende et al., 2015). No significant difference was found in maximum average fracture force or hardness for the 3 formulations: F7, F10 and control (Table 3 ). This is a desirable result due to relationship with the chocolate texture acceptability. Rezende et al. (2015) mentioned that chocolates with added fibers such as inulin showed lower hardness than control (with sucrose), whereas samples with maltitol and without fiber resulted in hardness values close to control. No significant difference was found in Casson yield stress $\left(\tau_{\mathrm{Ca}}\right)$ and Casson viscosity $\left(\eta_{\mathrm{Ca}}\right)$ for the 3 formulations (Table 3 ). Although there were no statistically significant differences in $\tau_{\mathrm{Ca}}$ and $\eta_{\mathrm{Ca}}$, it is important to note that these properties are mainly affected by the distribution of particle size and ingredients used (Gonçalves \& Lannes, 2010). The hygroscopicity of sucrose substitutes affects moisture content of samples and likewise this influences viscosity. There is then a direct relationship between moisture content and Casson viscosity (Abbasi \& Farzanmehr, 2009).

Table 3. Maximum fracture force, Casson yield stress $\left(\tau_{\mathrm{Ca}}\right)$ and Casson viscosity $\left(\eta_{\mathrm{Ca}}\right)$ of control, F7 and F10 samples.

\begin{tabular}{cccc}
\hline Sample & $\begin{array}{c}\text { Maximum } \\
\text { fracture force }(\mathrm{N})\end{array}$ & $\tau_{\mathrm{Ca}}(\mathrm{Pa})$ & $\eta_{\mathrm{Ca}}\left(\mathrm{Pa}^{\star} \mathrm{S}\right)$ \\
\hline Control & $22.13 \pm 2.09^{\mathrm{a}}$ & $7.68 \pm 1.17^{\mathrm{a}}$ & $0.924 \pm 0.342^{\mathrm{a}}$ \\
F7 & $18.77 \pm 1.11^{\mathrm{a}}$ & $10.84 \pm 2.10^{\mathrm{a}}$ & $1.18 \pm 0.15^{\mathrm{a}}$ \\
F10 & $17.71 \pm 1.98^{\mathrm{a}}$ & $8.61 \pm 2.54^{\mathrm{a}}$ & $1.12 \pm 0.202^{\mathrm{a}}$ \\
\hline
\end{tabular}

Values correspond to the average and standard deviation of three replicates. Mean values with different letters in the same column show statistically significant differences $(\mathrm{p}<0.05)$. 
In the present study, a positive item to achieve productive processes and suitable products was the synergy between polydextrose and inulin, in combination with maltitol and stevia (F10), where the rheological variables were close to those of control sample. Regarding the formulation containing maltitol and stevia (F7) and as in the study reported by Sokmen \& Gunes (2006), Casson viscosity of the formulation with sucrose (control) was very similar to the sugar-free sample containing maltitol. This result is positive, since F7 is an appropriate formulation as an alternative to sugar-free chocolate, keeping rheological conditions necessary for processes and good quality products. Rheological properties of chocolate are important basically for two reasons: First, correct viscosity involves the production of very good quality products and manufacturing processes without technical drawbacks. Secondly, the perceived taste of chocolate depends upon the order and speed of contact, which is related to its viscosity and melting rate (Beckett, 2009).

\subsection{Nutritional information analysis}

According to nutritional tables resulting from F7 and F10 formulations and compared to control sample, $\mathrm{F} 7$ had a reduction in calories of $9.1 \%$ with a recommended portion of $20 \mathrm{~g}$. It makes possible to point out on the front face label that the product does not contain added sugar, which refers exclusively to the addition of sucrose, and it is reduced in calories, since a comparative statement is being made with respect to the formulation with sucrose that is currently on the market. A reduction in calories of $18.2 \%$ was also found for F10 and it is possible to make a declaration of important nutritional properties, which is "good source of fiber", because the recommended portion of $20 \mathrm{~g}$ contains $16 \%$ of the reference value of this nutrient and the Colombian standard requires a value between $10 \%$ and $19 \%$ for making this statement. Likewise, F10 can state on the front face label of the packaging material that the product does not contain added sugar and it is reduced in calories for the reasons explained above (Resolution Number 333, 2011).

\section{Conclusions}

It is possible to make sugar-free milk chocolate through the use of bulking agents (maltitol, polydextrose and inulin) in synergy with a non-caloric sweetener (stevia), preserving their sensory, rheological, textural, and quality properties. Two formulations were obtained: F7 with maltitol and stevia; and F10 with maltitol, polydextrose, inulin and stevia, which presented the best sensory and textural performance in relation to control samples (with sucrose). Moreover, these sugar-free samples showed a better sensory scores in terms of overall liking, melting rate, chocolate and dairy flavor. Polydextrose contents higher than $25 \%$ can significantly impact the texture of a chocolate product, interfering with the overall liking of the consumer and therefore it is important to consider a moderate presence of this ingredient. In samples containing stevia, the bitter attribute related to chocolate flavor may be confused because stevia has significant bitter taste residual associations in the mouth, produced by the presence of stevioside. Flow properties of chosen sugar-free samples do not represent a problem for the process on an industrial scale. F10 formulation has a competitive advantage over F7 formulation; the possibility of making the following nutritional declarations based on Colombian legislation: good source of fiber, without added sugar, and reduced in calories.

\section{References}

Abbasi, S., \& Farzanmehr, H. (2009). Optimization of the formulation of prebiotic milk chocolate based on rheological properties. Food Technology and Biotechnology, 47(4), 396-403.

Afoakwa, E. O., Paterson, A., \& Fowler, M. (2007). Factors influencing rheological and textural qualities in chocolate - a review. Trends in Food Science \& Technology, 18(6), 290-298. http://dx.doi.org/10.1016/j. tifs.2007.02.002.

Aidoo, R. P., Afoakwa, E. O., \& Dewettinck, K. (2014). Optimization of inulin and polydextrose mixtures as sucrose replacers during sugar-free chocolate manufacture - Rheological, microstructure and physical quality characteristics. Journal of Food Engineering, 126, 35-42. http://dx.doi.org/10.1016/j.jfoodeng.2013.10.036.

Aidoo, R. P., Depypere, F., Afoakwa, E. O., \& Dewettinck, K. (2013). Industrial manufacture of sugar-free chocolates - Applicability of alternative sweeteners and carbohydrate polymers as raw materials in product development. Trends in Food Science \& Technology, 32(2), 84-96. http://dx.doi.org/10.1016/j.tifs.2013.05.008.

Beckett, S. T. (2009). Industrial chocolate manufacture and use (4th ed.). United Kingdom: Wiley Blackwell.

Edwards, C. H., Rossi, M., Corpe, C. P., Butterworth, P. J., \& Ellis, P. R. (2016). The role of sugars and sweeteners in food, diet and health: Alternatives for the future. Trends in Food Science \& Technology, 56, 158-166. http://dx.doi.org/10.1016/j.tifs.2016.07.008.

Farzanmehr, H., \& Abbasi, S. (2009). Effects of inulin and bulking agents on some physicochemical, textural and sensory properties of milk chocolate. Journal of Texture Studies, 40(5), 536-553. http:// dx.doi.org/10.1111/j.1745-4603.2009.00196.x.

Folkenberg, D. M., Bredie, W. L. P., \& Martens, M. (1999). Sensoryrheological relationships in instant hot cocoa drinks. Journal of Sensory Studies, 14(2), 181-195. http://dx.doi.org/10.1111/j.1745459X.1999.tb00111.x.

Glicerina, V., Balestra, F., Dalla Rosa, M., \& Romani, S. (2016). Microstructural and rheological characteristics of dark, milk and white chocolate: A comparative study. Journal of Food Engineering, 169, 165-171. http://dx.doi.org/10.1016/j.jfoodeng.2015.08.011.

Gomes, C. R., Vissotto, F. Z., Fadini, A. L., Faria, E. V., \& Luiz, A. M. (2007). Influência de diferentes agentes de corpo nas características reológicas e sensoriais de chocolates diet em sacarose e light em calorias. Food Science and Technology, 27(3), 614-623. http://dx.doi. org/10.1590/S0101-20612007000300029.

Gonçalves, E. V., \& Lannes, S. C. S. (2010). Chocolate rheology. Food Science and Technology, 30(4), 845-851. http://dx.doi.org/10.1590/ S0101-20612010000400002.

Instituto Colombiano de Normas Técnicas y Certificación - ICONTEC. (1996). Norma Técnica Colombiana 3929 - Análisis Sensorial. Metodología. Métodos del Perfil de Sabor (NTC 3929). Bogotá: ICONTEC.

Instituto Colombiano de Normas Técnicas y Certificación - ICONTEC. (1998). Norma Técnica Colombiana 4489 - Metodología. Perfil de Textura (NTC 4489). Bogotá: ICONTEC.

Instituto Colombiano de Normas Técnicas y Certificación - ICONTEC. (2014). Guía técnica colombiana 245 - Análisis sensorial. Guía general para la selección, entrenamiento y seguimiento de evaluadores (GTC 245). Bogotá: ICONTEC. 
Khattab, S. N., Massoud, M. I., Jad, Y. E., Bekhit, A. A., \& El-faham, A. (2015). Production and physicochemical assessment of new stevia amino acid sweeteners from the natural stevioside. Food Chemistry, 173, 979-985. http://dx.doi.org/10.1016/j.foodchem.2014.10.093. PMid:25466115.

Markey, O., Lovegrove, J. A., \& Methven, L. (2015). Sensory profiles and consumer acceptability of a range of sugar-reduced products on the UK market. Food Research International, 72, 133-139. http:// dx.doi.org/10.1016/j.foodres.2015.03.012.

Oliveira, D., Antúnez, L., Giménez, A., Castura, J. C., Deliza, R., \& Ares, G. (2015). Sugar reduction in probiotic chocolate-flavored milk: Impact on dynamic sensory profile and liking. Food Research International, 75, 148-156. http://dx.doi.org/10.1016/j.foodres.2015.05.050. PMid:28454942.

Rezende, N. V., Benassi, M. T., Vissotto, F. Z., Augusto, P. P. C., \& Grossmann, M. V. E. (2015). Effects of fat replacement and fibre addition on the texture, sensory acceptance and structure of sucrosefree chocolate. International Journal of Food Science \& Technology, 50(6), 1413-1420. http://dx.doi.org/10.1111/ijfs.12791.

Rocha, I. S., Santana, L. R. R., Soares, S. E., \& Bispo, E. S. (2017). Effect of the roasting temperature and time of cocoa beans on the sensory characteristics and acceptability of chocolate. Food Science and Technology, 37(4), 522-530. http://dx.doi.org/10.1590/1678-457x.16416.

Shah, A. B., Jones, G. P., \& Vasiljevic, T. (2010). Sucrose-free chocolate sweetened with Stevia rebaudiana extract and containing different bulking agents - effects on physicochemical and sensory properties. International Journal of Food Science \& Technology, 45(7), 1426-1435. http://dx.doi.org/10.1111/j.1365-2621.2010.02283.x.

Sokmen, A., \& Gunes, G. (2006). Influence of some bulk sweeteners on rheological properties of chocolate. Lebensmittel-Wissenschaft + Technologie, 39(10), 1053-1058. http://dx.doi.org/10.1016/j. lwt.2006.03.002.

Son, Y., Choi, S., Yoo, K., Lee, K., Lee, S., Hwang, I., \& Kim, S. (2018). LWT - Food Science and Technology Anti-blooming effect of maltitol and tagatose as sugar substitutes for chocolate making. Lebensmittel-Wissenschaft + Technologie, 88, 87-94. http://dx.doi. org/10.1016/j.lwt.2017.09.018.

Tavares, C. F., Geraldo, A. P. G., Ramos, J. F., \& Pinto-e-Silva, M. E. M. (2014). Impact of the use of Non-Caloric Sweeteners on the Development and Acceptibility of Sweet Preparations. Journal of Culinary Science \& Technology, 12(3), 229-241. http://dx.doi.org/1 0.1080/15428052.2014.884957. 